E3S Web of Conferences 1, 37006 (2013)

DOI: $10.1051 / \mathrm{e} 3 \operatorname{sconf} / 20130137006$

(c) Owned by the authors, published by EDP Sciences, 2013

\title{
Functionalized Nanoporous Track-Etched b-PVDF Membrane Electrodes for Heavy Metal Determination by Square-Wave Anodic Stripping Voltammetry
}

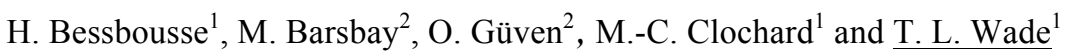 \\ ${ }^{1}$ Laboratoire des Solides Irradiés, CEA-CNRS-Ecole Polytechnique, 91128 Palaiseau, France \\ haad.bessbousse@polytechnique.edu,travis.wade@polytechnique.edu \\ ${ }^{2}$ Hacettepe University Department of Chemistry, Polymer Chemistry Division, 06800 Beytepe Ankara Turkey
}

\begin{abstract}
Track-etched functionalized nanoporous $\beta$-PVDF membrane electrodes, or functionalized membrane electrodes (FMEs), are electrodes made from track-etched, poly(acrylic acid) (PAA) functionalized nanoporous $\beta$-poly(vinylidene fluoride) ( $\beta$-PVDF) membranes with thin porous Au films sputtered on each side as electrodes. To form the $\beta$-PVDF nanoporous membranes, $\beta$-PVDF films are irradiated by swift heavy ions. After irradiation, radical tracks are stable in the membranes. Chemical etching removes some of the radical tracks revealing nanopores. Radicals, remaining in the pores, initiate radio grafting of PAA from the pore walls of the nanoporous $\beta$-PVDF. PAA is a cation exchange polymer that adsorbs metal ions, such as $\mathrm{Pb}^{2+}$, from aqueous solutions thus concentrating the ions into the membrane. After a calibrated time the FME is transferred to an electrochemical cell for square-wave anodic stripping voltammetry analysis.
\end{abstract}

Key words: Heavy metals, radio-grafting, membranes, nanopores, electro active polymer, anodic stripping voltammetry (ASV)

\section{Introduction}

We have developed a new type of mercury free electrode based on track-etched poly(acrylic acid) (PAA) functionalized nanoporous $\beta$-poly(vinylidene fluoride) $(\beta$-PVDF) membranes with porous gold conductive layers on each side (Figure 1) . (Bessbousse, et al. 2011) The grafted PAA inside the pores is a adsorbing agent for some heavy metal ions. It acts as a sponge to pre-concentrate the ions prior to ASV analysis thus allowing the collection of the analytes without having to collect samples.

\section{Materials and Methods}

$\beta$-poly(vinylidene fluoride) ( $\beta$-PVDF) films of $9 \mu \mathrm{m}$ thickness were provided by PiezoTech SA. Potassium hydroxide, potassium permanganate, potassium disulfite, acrylic acid (AA), and Mohr's salt $\left(\left(\mathrm{NH}_{4}\right)_{2} \mathrm{Fe}\left(\mathrm{SO}_{4}\right)_{2}\right.$ $\left.6 \mathrm{H}_{2} \mathrm{O}\right)$ were purchased from Sigma-Aldrich.

Irradiation: The irradiation was performed at the GANIL irradiation centre (Caen, France). Films were irradiated with $\mathrm{Kr}$ ions $\left(10.37 \mathrm{Mev} / \mathrm{amu}\right.$, fluence $10^{7}$ to
$10^{10} \mathrm{~cm}^{-2}$ ) in a He atmosphere. The irradiated films were stored at $-20^{\circ} \mathrm{C}$ in a $\mathrm{N}_{2}$ atmosphere until chemical etching and radio grafting.

Chemical etching: $\beta$-PVDF irradiated films were chemically etched using permanganate solution $(0.25 \mathrm{M})$ in a highly alkaline medium $(\mathrm{KOH}, 10 \mathrm{M})$ at $65^{\circ} \mathrm{C}$ for 30 min. After etching the obtained membranes were washed in potassium disulfite solution (15\%) and de-ionized water. The $\mathrm{KOH}$ solution is very corrosive and should only be handled in a fume hood wearing protective clothing, gloves, and safety glasses. The used $\mathrm{KOH}$ solution should be disposed of as corrosive waste.

Radiografting: Etched $\beta$-PVDF films were immersed at room temperature into a radio grafting solution containing AA and Mohr's salt $(0.25 \% \mathrm{w} / \mathrm{w})$ in a purge able glass tube and then connected to a Schlenk line. After $15 \mathrm{~min}$ of $\mathrm{N}_{2}$ bubbling at room temperature, the glass tube was sealed and put into a thermo stated water bath at $60^{\circ} \mathrm{C}$ for $1 \mathrm{~h}$. The radio grafted film was washed with water and then Sohxlet extracted in boiling water for 24 hours in order to extract free homopolymer. The membrane was dried at $50^{\circ} \mathrm{C}$ under vacuum overnight. 
The acrylic acid solution is very corrosive and should only be handled in a fume hood wearing protective clothing, gloves, and safety glasses. The used acrylic acid solution should be disposed of as corrosive waste.

Solutions: Heavy metal $\left(\mathrm{Co}^{2+}, \mathrm{Ni}^{2+}\right.$, and $\left.\mathrm{Pb}^{2+}\right)$ standard solutions were diluted from $1.000 \mu \mathrm{g} / \mathrm{mL}$ AAS calibration standards (Alfa Aesar). The electrolyte for the voltammetry measurements was $0.1 \mathrm{M}$ sodium acetate adjusted to $\mathrm{pH} 4.5$ with acetic acid (Sigma-Aldrich). All solutions were made with $18 \mathrm{Mohm}$ deionised water (Aquadem Veolia). $100 \mathrm{ml}$ polypropylene containers (VWR) were used for dilution and analysis to avoid loss of metal ions due to surface adsorption on glass.(Pinheiro and Bosker 2004) The metal solutions are poisonous so gloves should be worn when handling and the solutions should be disposed of as toxic waste.

Connections: The functionalized membrane was metalized by gold sputtering on both sides with a K550 gold sputter (EMITECH) with a sputtering current of 40 $\mathrm{mA}$ in an argon atmosphere of $10^{-2}$ bar through a mask with $0.4 \mathrm{~cm}$ diameter holes for 3 minutes. Under these conditions the gold sputtering rate is $12 \mathrm{~nm} /$ minute. Gold sputtering targets were purchased from NewMet (New Metals \& Chemicals LTD).

Voltammetry: The voltammetry and other electrochemical measurements were performed in a three-compartment electrochemical cell controlled by a PalmSens potentiostat (PalmSens). Ag/ $\mathrm{AgCl}(3 \mathrm{M} \mathrm{KCl})$ reference electrodes (METROHM) were used for all measurements. The parameters for the SW-ASV analysis were a frequency of $25 \mathrm{~Hz}$, step amplitude of $25 \mathrm{mV}$ and a potential increment of $4 \mathrm{mV}$.

\section{Results and Discussion}

$\beta$-PVDF polymer films are first bombarded by swift heavy ions and the tracks formed along the ion passage are revealed under alkaline chemical treatment. After etching times of less than one hour, the radical residues within the nanopore walls were sufficient for radio grafting .(Cuscito, et al. 2007) This is due to the property of $\beta$-PVDF favouring the radical stability by trapping them inside its crystalline areas.(Aymes-Chodur, et al. 1999; Aymes-Chodur, et al. 2001) Acrylic acid can then be selectively radio grafted into the pore walls giving a polyacrylic acid functionalisation to the nanopores.

To transform the functionalized membranes into electrodes, a thin $(\sim 50 \mathrm{~nm}) \mathrm{Au}$ film is sputtered onto each surface to provide good conductive layer without blocking the pores. Following the $\mathrm{Au}$ film sputtering through a mask a $1.5 \times 0.6 \mathrm{~cm}$ square of membrane is cut out and connected to stainless steel wires with silver paste. The contacts are first protected with hot wax and then fingernail polish.

During the immersion of a FME in a sample containing heavy metal ions, the PAA grafted in the membrane complexes some of the metal cations, equation 1 .

$$
\mathrm{M}^{\mathrm{n}+}+\mathrm{R}-\mathrm{COO}^{-}<-->\mathrm{R}-\mathrm{COO}^{-} \mathrm{M}^{\mathrm{n}+}
$$

For the electrochemical analysis the FME is connected to a potentiostat and placed at a negative potential. The negative potential reduces the absorbed metals ions that are very close to the working electrode, from the poly (acrylic acid) in the pores to their metallic state at the $\mathrm{Au}$ surface, equation 2 .

$$
\mathrm{R}-\mathrm{COO}^{-} \mathrm{M}^{\mathrm{n}+}+\mathrm{ne}^{--->} \mathrm{M}(\mathrm{Au})
$$

After the reduction, square wave anodic stripping voltammetry (SW-ASV) analysis is performed in order to oxidize the metal from the working electrode surface and measure the resulting current.

Figure 1a shows the SW-ASV analysis of a solution containing $25 \mathrm{ppb}$ of $\mathrm{Co}^{2+}, 10 \mathrm{ppb}$ of $\mathrm{Ni}^{2+}$ and $25 \mathrm{ppb}$ of $\mathrm{Pb}^{2+}$. Oxidation peaks for $\mathrm{Ni}$ and $\mathrm{Pb}$ are seen at $-0.53 \mathrm{~V}$ and $-0.05 \mathrm{~V}$ respectively. No oxidation peak was observed for $\mathrm{Co}^{2+}$ which is more negative than $\mathrm{Ni}^{2+}$ and could not be detected in the high background at more negative potentials. Figure $1 \mathrm{~b}$ is a plot of superimposed SW-ASV current peaks for different concentrations of $\mathrm{Pb}^{2+}$ (1.0 to $100.0 \mathrm{ppb}$ ) along with a blank scan. Each curve was obtained using a different FME. The charge associated with each curve gave a linear plot with a $\mathrm{R}^{2}$ of 0.9950 .

\section{Conclusion}

We have developed and characterized a new nanoporous mercury-free electrode functionalized with PAA. The PAA in the electrode can complex and concentrate metal cations from solutions at open circuit. Using SW-ASV on the FME we were able to detect $\mathrm{Ni}^{2+}$ and $\mathrm{Pb}^{2+}$ after immersion in a solution containing $\mathrm{Co}^{2+}, \mathrm{Ni}^{2+}$ and $\mathrm{Pb}^{2+}$. The lack of a signal for $\mathrm{Co}^{2+}$ was not seen due to high background current. A very clean reduction peak for $\mathrm{Pb}^{2+}$ was seen and the analysis parameters were optimised.

\section{Acknowledgements}

The research described here has been supported by Triangle de la physique contract 2009-042T and the Department d'Enseignement-Recherche de Physique de l'ECOLE Polytechnique, OSEO and the CEA TECHSAN program. The authors would also like to acknowledge Dr Emmanuel Balanzat from CIMAP at GANIL for his invaluable assistance for Swift Heavy Ion Irradiation.

\section{References}

Aymes-Chodur C, Betz N, Porte-Durrieu M-C, Baquey C, Le Moel A. A FTIR and SEM study of PS radiation grafted fluoropolymers: influence of the nature of the ionizing radiation on the film structure. Nuclear Instruments \& Methods in Physics Research Section B-Beam Interactions with Materials and Atoms 1999; 151:377-385. 


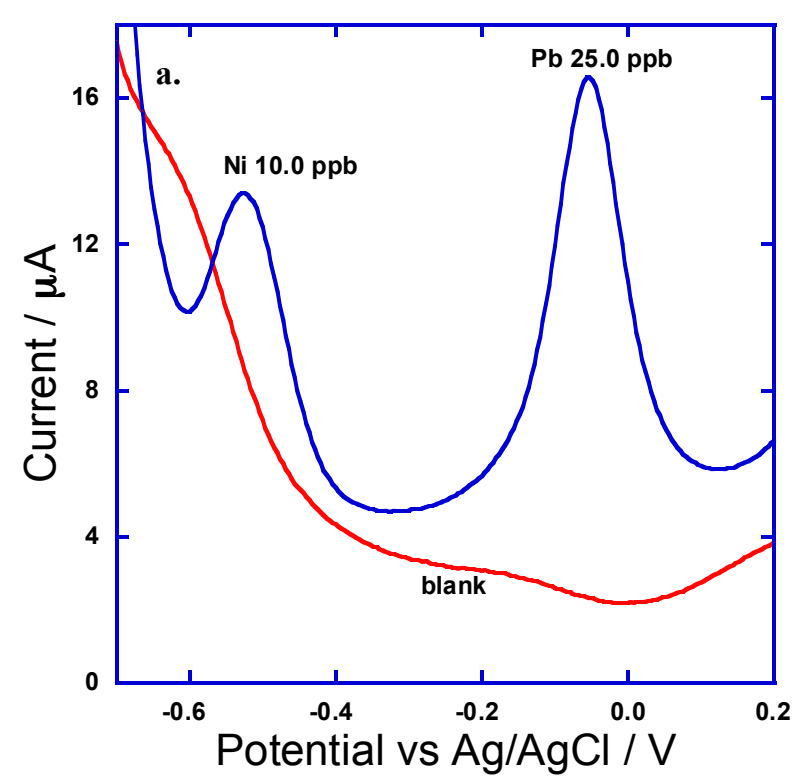

Fig. 1a. SW-ASV analysis of FME after immersion in 50 $\mathrm{ml}$ of a stirred solution of $25 \mathrm{ppb} \mathrm{Co}^{2+}, 10 \mathrm{ppb} \mathrm{Ni}{ }^{2+}$ and $25 \mathrm{ppb} \mathrm{Pb}^{2+}$ for 30 minutes. The curve from a blank analysis is also plotted (red dashed).

Aymes-Chodur C, Esnouf S, Le Moel A. ESR studies in gamma-irradiated and PS-radiation-grafted poly(vinylidene fluoride). Journal of Polymer Science Part B-Polymer Physics 2001; 39:1437-1448.

Bessbousse H, Nandhakumar I, Decker M, Barsbay M, Cuscito O, Lairez D, Clochard M-C, Wade TL. Functionalized nanoporous track-etched beta-PVDF membrane electrodes for lead(II) determination by square wave anodic stripping. Analytical Methods 2011; 3:1351.

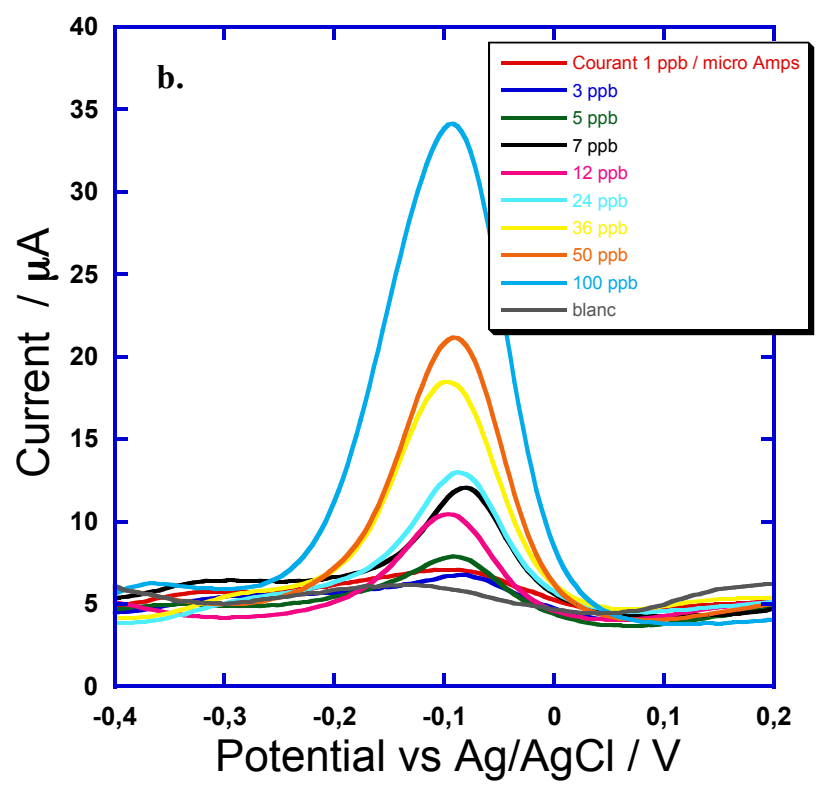

Fig. 1b. SW-ASV analysis plots of FMEs after immersion in $50 \mathrm{ml}$ of stirred $\mathrm{Pb}^{2+}$ ion solutions for 30 minutes using different concentrations.

Cuscito O, Clochard M-C, Esnouf S, Betz N, Lairez D. Nanoporous beta-PVDF membranes with selectively functionalized pores. Nuclear Instruments \& Methods In Physics Research Section B-Beam Interactions With Materials And Atoms 2007;265:309-313.

Pinheiro JP, Bosker W. Polystyrene film-coated glassware: a new means of reducing metal losses in trace metal speciation. Analytical and Bioanalytical Chemistry 2004; 380:964-968. 